\title{
Elastofibroma dorsi: 8 case reports and a literature review
}

\author{
F. Muratori - M. Esposito • F. Rosa - F. Liuzza • \\ N. Magarelli • B. Rossi • H.M. Folath • F. Pacelli • \\ G. Maccauro
}

Received: 28 July 2007 / Accepted: 29 December 2007 / Published online: 17 March 2008

\begin{abstract}
A series of 8 cases of elastofibroma is reported, and the clinical, pathological and imaging features and different therapeutic modalities are reviewed. On this basis, we suggest an algorithm for the diagnosis and treatment of elastofibroma. Briefly, marginal excision is the treatment of choice in symptomatic patients, while followup appears to be a good solution in asymptomatic ones.
\end{abstract}

Keywords Elastofibroma $\cdot$ Dorsi $\cdot$ Scapula $\cdot$ Excision

\section{F. Muratori}

First Division of Orthopaedics

San Pietro Hospital

Rome, Italy

M. Esposito · F. Liuzza · B. Rossi · H.M. Folath · G. Maccauro (凶) Department of Orthopaedics

Catholic University

Rome, Italy

e-mail: giuliomac@tiscali.it

F. Rosa $\cdot$ F. Pacelli

Department of Clinical Surgery

Catholic University

Rome, Italy

N. Magarelli

Department of Radiology

Catholic University

Rome, Italy

\section{Introduction}

Elastofibroma dorsi is a rare pseudotumor developing in a highly characteristic anatomical location. In fact, it is usually localized anterior to the inferior pole of the scapula and the serratus anterior muscle over the ribs of the thoracic cage. Very rarely, elastofibroma is found in other sites, such as the tip of the elbow, near the ischial tuberosities, the deltoid muscle, foot, inguinal region, orbits, stomach, greater omentum and the intraspinal spaces [1-10]. It is relatively frequent among elderly women, with a mean age at onset of 70 years. It is bilateral in $10 \%$ of cases $[1,8,10]$.

We reported a series of eight patients affected by elastofibroma. We discuss the clinical and radiological features and treatment modalities and review the literature concerned.

\section{Case series}

Seven women and one man of mean age 61 years (range, 47-82 year) were treated for elastofibroma during the period from 2000 to 2004 (Table 1). All had unilateral lesions except one woman who had bilateral masses. Every case was studied with radiography, ultrasound, computed tomography (CT) and gadolinium (MRI) enhanced magnetic versonance imaging. The patients were divided into 2 groups: asymptomatic ( 2 cases) and symptomatic (6 cases).

The asymptomatic patients were treated conservatively, and achieved a good range of motion without any increase of the mass's dimensions 14 and 15 months after the diagnosis. The 6 symptomatic cases, complaining of snapping of the scapula, were treated surgically by mar- 
Table 1 Clinical characteristics of 8 patients with elastofibroma

\begin{tabular}{|c|c|c|c|c|c|c|}
\hline Patient & Sex & Age (years) & Location & Size $(\mathrm{cm})$ & Treatment & Follow-up (months) \\
\hline 1 & $\mathrm{~F}$ & 47 & Right & 5.3 & Surgery & 18 \\
\hline 2 & $\mathrm{~F}$ & 63 & Right & 4.9 & Surgery & 25 \\
\hline 3 & $\mathrm{~F}$ & 59 & Left & 11.7 & Surgery & 37 \\
\hline 4 & $\mathrm{~F}$ & 82 & Right & 3.8 & Conservative & 15 \\
\hline 5. & M & 58 & Right & 6.18 & Surgery & 29 \\
\hline 6 & $\mathrm{~F}$ & 68 & Bilateral & $7.8-6.9$ & Surgery & 24 \\
\hline 7 & $\mathrm{~F}$ & 54 & Left & 3.5 & Conservative & 14 \\
\hline 8. & $\mathrm{~F}$ & 57 & Left & 6.9 & Surgery & 27 \\
\hline
\end{tabular}

ginal excision of the mass without performing a preliminary biopsy. Postoperatively, the operated shoulders were immobilized with a support for 3 weeks followed by rehabilitation and physical therapy. These patients were followed for a mean period of 27 months (range, 18-37 months). During this period, no recurrence of the elastofibroma was observed, and the patients were pain free with a completely normal shoulder range of motion.

\section{Discussion}

Elastofibroma is a rare lesion. In fact most publications [1-6, 8-10] reported either a single case or a small series of 2-7 cases, except for Nagamine et al. [7] who reported a study of 170 cases. These lesions tend to be slowly growing and asymptomatic in more than $50 \%$ of the cases. When symptoms are present, they are typical, consisting of local scapular swelling and a clunking sensation during abduction and adduction of the shoulder, with pain of moderate or, rarely, severe entity $[2,3,5]$.

The location of elastofibromas and its incidence among older individuals may be related to the natural existence of fibro-elastic tissue in this region and suggests a reactive process in response to friction of the scapula against the ribs [2, 3, 10]. Alternatively, the genesis of elastofibroma is thought to involve an overproduction of the collagenous connective tissue with a degeneration of the collagen fibres and an overproduction of immature elastic tissue, derived from fibroblasts, alternating with deposition of hyperplastic fat $[2,8,10]$. Genetic factors may also be involved $[2,8,10]$.

Ultrasound examination shows an abnormal mass of tissue in the typical location of the elastofibroma with an alternating pattern of hyperechogenic and hypoechogenic lines that are roughly parallel to the chest wall (Fig. 1). MRI is considered to be the investigation of choice because it shows the alternating pattern of fibrous and fatty tissues (Fig. 2). The lesions appear poorly circumscribed, heterogeneous with the margins that may be sharp and indistinct. On T1-weighted and T2-weighted sequences, fibrous tissue produces low-intensity signals identical to that produced by muscular tissue, while the fatty tissue is seen as a high-intensity signal on T1weighted sequences and as an intermediate signal on T2weighted sequences. Streaks of fatty tissue alternate with

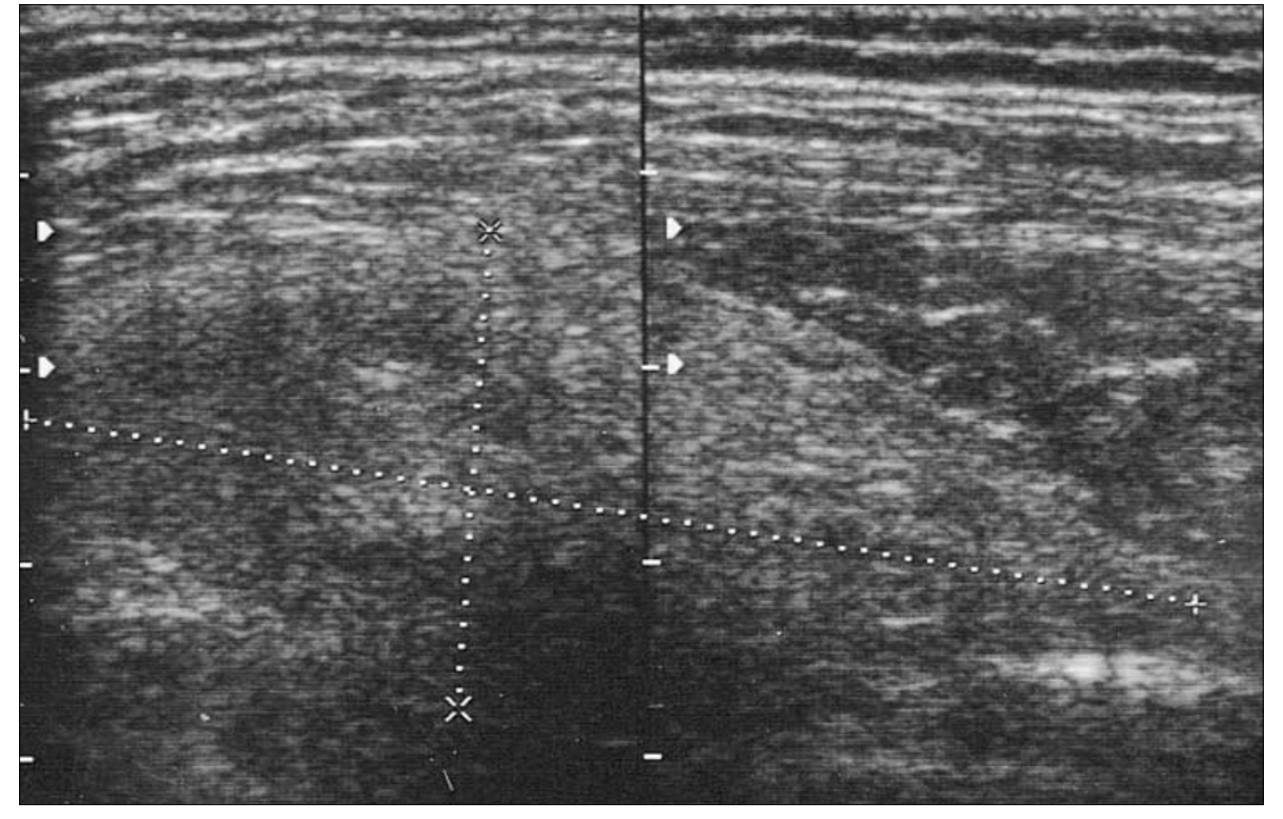

Fig. 1 Ultrasound examination shows an abnormal mass in a location typical of elastofibroma, with an alternating pattern of hyperechogenic and hypoechogenic lines 

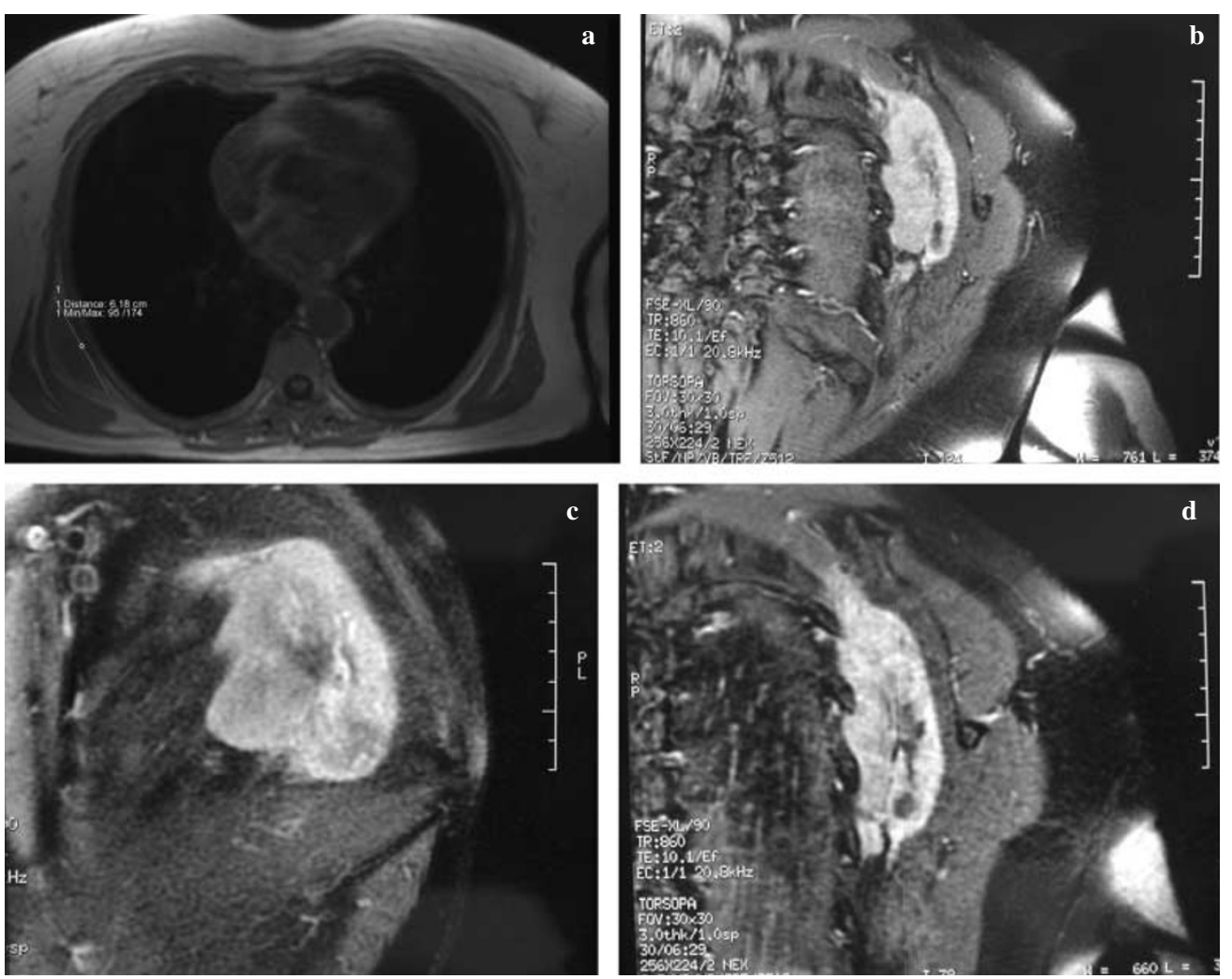

Fig. 2a-d T1-weighted $M R$ images. a Axial image shows a hypo-intense solid mass under the right scapula within the muscular tissue of the posterior thoracic wall. The diameter of this mass with a regular contour is $6.18 \mathrm{~cm}$. b-d After the infusion of gadolinium with fat suppression technique, MRI shows a prevalent peripheral enhancement with a central hypo-intensity due to fat tissue. A ill defined mass appears without bone or surrounding soft tissue infiltration and is localized between the subscapularis muscle and the posterior thoracic wall

Fig. 3 Histological analysis shows characteristic structure with alternating streaks of fatty tissue and strands of fibrous tissue

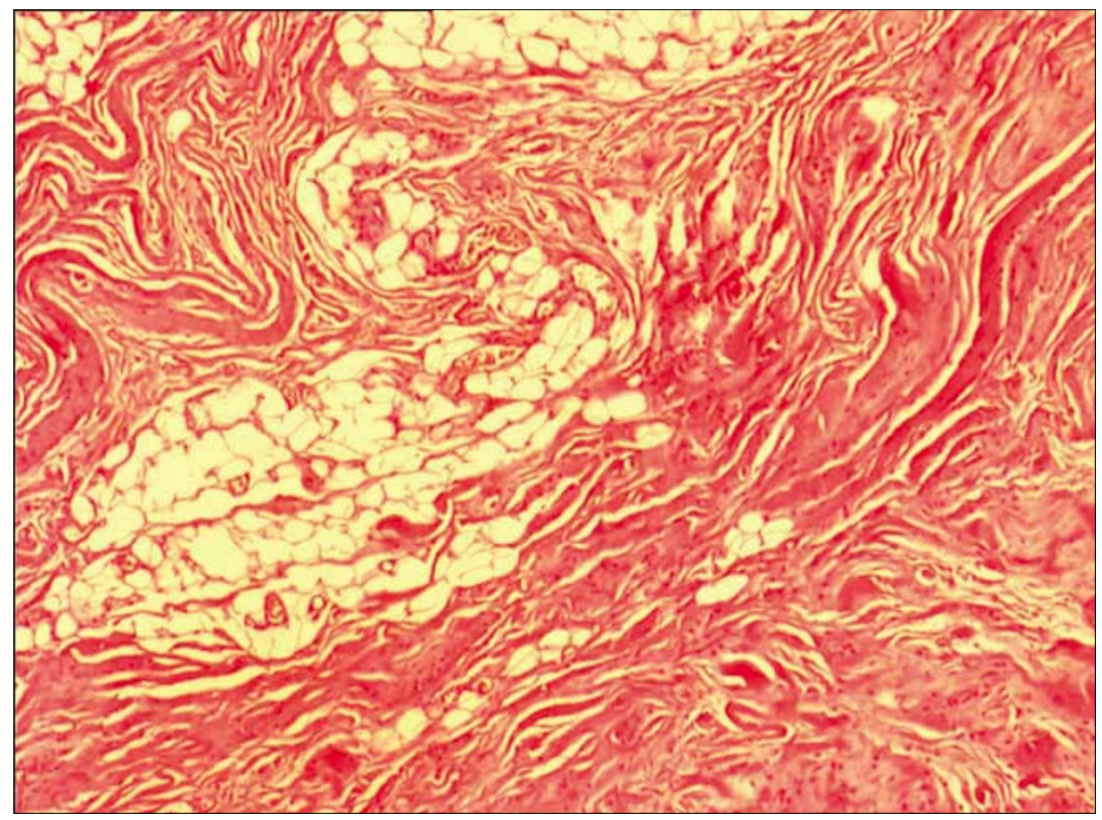

strands of fibrous tissue forming straight or curved lines. On STIR sequences, the mass is seen as a mosaic of low and high intensity areas. The elastofibroma appears as a large mass with ill-defined contours and marked gadolinium enhancement $[6,8-10]$. CT is less sensitive than MRI in visualizing the fatty tissue, so that the elastofibroma may be seen as a homogeneous mass with a density inferior to that of muscles. Moreover, CT shows the absence of bone abnormalities.
Elastofibroma exhibits a characteristic structure where streaks of fatty tissue are alternated with strands of fibrous tissue. The hypertrophic fibrous tissue contains fibrillated material with identical staining affinities to that of necrotic fibrous tissue, muscle, and fat (Fig. 3).

Routine biopsy has been considered to rule out soft tissue sarcoma [4-9]. On the contrary, most of the recent publications indicate that biopsy is unnecessary when the MRI findings are sufficiently typical $[1-3,5,6,8]$. In particular, 


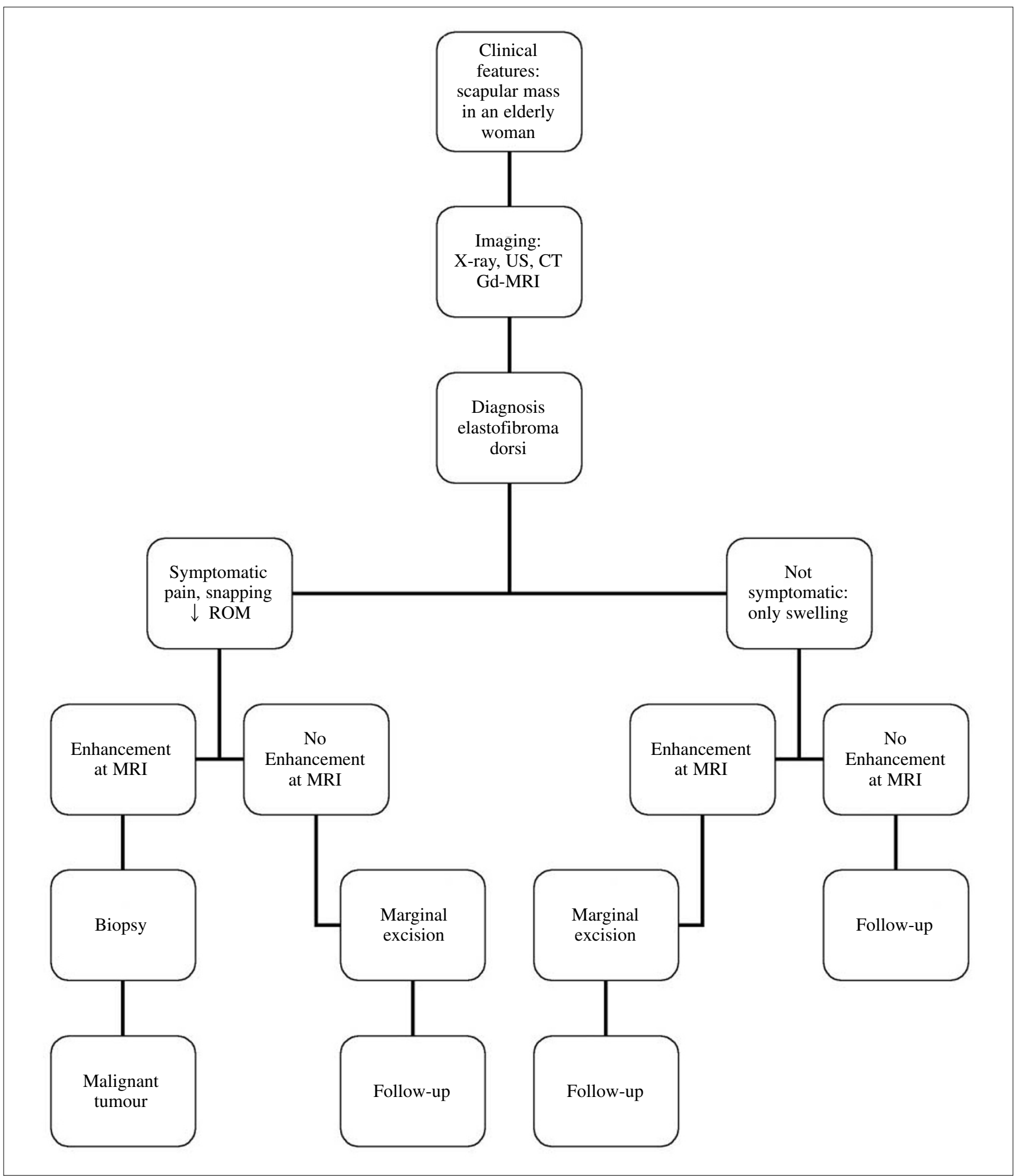

Fig. 4 Diagnostic and therapeutic algorithm proposed for elastofibroma

Hayes et al. [2] suggested a core biopsy only in case of suspicion of a soft tissue sarcoma. Turna et al. [9] considered a histological evaluation by intra-operative frozen section and performed complete resection in case of a benign histological results. On the other hand, Vastamaki [10] considered incisional biopsy unnecessary when the clinical findings are typical; thus biopsy is indicated only when the sub-scapular mass has enlarged very quickly within a few months.

Concerning the modalities of treatment, controversy is reported in the literature. Marginal excision has been sug- 
gested because it carries a low recurrence risk $[1,5$, 8-10], and no malignant transformation has been reported. Guha and Reja [1] mentioned the marginal surgical excision for these lesions and reported only one case of recurrence after the excision; another case was successfully treated with radiotherapy. Malghem et al. [6] adopted a wait and see approach in asymptomatic patients: since these patients did not develop symptoms, the authors concluded that elastofibroma is an ungrowing lesion after the diagnosis.

Considering these reports, we suggest a diagnostic and therapeutic algorithm for elastofibroma (Fig. 4). In case of a scapular region mass in an elderly woman, radiography, ultrasound and MRI with gadolinium enhancement are required. If the patient is asymptomatic and there is no enhancement on MRI, clinical follow-up is sufficient. On the other hand, in symptomatic patients with no enhancement, marginal excision of the mass is necessary. Marginal excision is also indicated in the absence of symptoms in the presence of enhancement on MRI. We recommend biopsy to rule out sarcoma when both symptoms and MRI enhancement are present.

\section{References}

1. Guha AR, Raja RCS (2004) Elastofibroma dorsi - A case report and review of literature. Int J Clin Pract 58:218-220

2. Hayes AJ, Alexander N, Clark MA, Thomas JM (2004) Elastofibroma: a rare soft tissue tumour with a pathognomonic anatomical location and clinical symptom. Eur J Surg Oncol 30:450-453

3. Heck S, Thomas G, Mader K et al (2003) Bilateral elastofibroma as unusual cause of shoulder pain Plast Reconstr Surg 112:1959-1961

4. Jarvi OH, Lansimies PH (1975) Sub clinical elastofibroma in the scapular region in an autopsy series. Acta Pathol Microbiol Scand 83:87-108

5. Majo J, Gracia I, Doncel A et al (2001) Guix M. Elastofibroma dorsi as a cause of shoulder pain or snapping scapula. Clin Orthop Relat Res 388:200-204

6. Malghem J, Baudrez V, Lecouvet F et al (2004) Imaging study findings in elastofibroma dorsi. Joint Bone Spine 71:536-541

7. Nagamine N, Nohara Y, Ito E (1982) Elastofibroma in Okinawa. A clinical-pathological study of 170 cases. Cancer 50:1794-1795

8. Oueslati S, Douira-Khomsi W, Bouaziz MC, Zaouia K (2006) Elastofibroma dorsi: a report on 6 cases. Acta Orthop Belg 72(2):237-242

9. Turna A, Yilmaz M.A, Urer N et al (2002) Bilateral elastofibroma dorsi. Ann Thorac Surg 73:630-632

10. Vastamaki M (2001) Elastofibroma Scapulae. Clin Orthop Relat Res 392:404-408 